\title{
Kelekatan Ayah-Anak sebagai Media Dasar Memberfungsikan Kejiwaan Positif Anak
}

\author{
Azam Syukur Rahmatullah \\ Program Doktor Psikologi Pendidikan Islam Pascasarjana \\ Universitas Muhammadiyah Yogyakarta \\ azamsyukurrrahmatullah@yahoo.co.id
}

\begin{abstract}
The Father having a great responsibility to care for the children, and they can not avoid it. The Result of the research is show if the father have to develop nearly and care attachment to the children since early (unborn child). Several done by the father; give attention to a baby, the dialogue with a baby, reading a prayer to a baby, touching a baby while wife's pregnancy. In the other hand, a father have to become "like a mother" after the baby born; wear and change the diapers, follow a mom to cleaning the faces, giving a milk, carry on a baby, and hug a baby. On going process to be an adult, a father must increasing to improve the attachment to the children, although he is busy. Communication between father to children or children to father should built by warm and intimate condition, and have to continuing. Hopely, The warm and intimate communication can make positive soul and alive soul to the children.
\end{abstract}

Keywords: Attachment, Positive Soul, Father-Child, Child-Father

\section{Pendahuluan}

Seorang anak dalam proses pertumbuhannya baik secara fisik, kejiwaan, spiritual membutuhkan "pendamping setia" yang tulus, tanpa syarat, dan memiliki dua sayap. Kedua sayap yang dimaksud adalalah ayah dan ibu yang bersatu padu memberikan pola asuh sehat, matang dan kaya kasih sayang. Seorang anak yang mengalami krisis pengasuhan yang positif dari kedua orang tua bisa menjadikan anak-anak menyimpang perilakunya. Hasil penelitian Violet Lai, Gerald Zeng, Chi Meng Chu menyatakan bahwa penyimpangan-penyimpangan yang dilakukan oleh kaum muda salah satu penyebabnya adalah "ketidakhadiran orang tua dalam menyentuh jiwa anak". Akibatnya, anak merasa sendiri bahkan ada di antaranya yang memiliki orang tua tetapi merasa tidak memiliki orang tua.

Hasil penelitian Beidi Dong, Marvin D Krohn menyatakan dengan jelas bahwa pola asuh orang tua yang buruk bisa menjadikan anak-anaknya mengalami problem dalam perilaku kesehariannya. Interaksi antara orang tua dan anak idealnya dibangun hangat dan tidak mengalami krisis kepercayaan dari anak kepada orang

${ }^{1}$ Violet Lai, Gerald Zeng, Chi Meng Chu, Violent and Nonviolent Youth Offenders: Preliminary Evidence on Group Subtypes, 2016, Doi: 10.1177/1541204015615193 
tua mereka. ${ }^{2}$ Oleh karenanya menjadi tanggung jawab orang tua untuk berupaya mendekat dan melekat kepada anak-anak mereka.

Penyimpangan perilaku anak nyatanya juga bisa terjadi karena anak hanya merasa dekat ibunya, atau ibu yang dekat serta lekat dengan anaknya, sedangkan anak tidak merasa dekat dengan ayahnya, meskipun sang ayah berada dalam satu rumah, meskipun ayah belum meninggal. Komunikasi yang terjadi antara anak dengan ayah merupakan komunikasi yang kering, artinya tidak ada interaksi dua arah antara ayah dan anak, atau antara anak dengan ayah. Meski berada dalam satu atap, antara ayah dan anak jarang ada tegur sapa, jarang terjadi perbincangan yang hangat dan mesra. Kondisi yang demikian dapat menjadikan anak-anak merasa asing di rumahnya sendiri.

Fakta yang terjadi di lapangan, menyatakan bahwa kebanyakan anak lebih dekat dengan ibunya tidak dengan ayahnya. Hasil penelitian Raden Dimas Bagus Prabowo dan Mita Aswanti menyatakan bahwa anak lebih lekat kepada ibunya daripada ayahnya, dengan prosentase kedekatan anak terhadap ayahnya hanya berkisar 9,7 \% sedangkan kedekatan anak dengan ibunya sekitar 37,9\%. ${ }^{3}$ Hasil penelitian Azam Syukur Rahmatullah dalam disertasinya (2013) juga menyatakan bahwa anak-anak bermasalah yang ditemui di Pondok Inabah Pondok Pesantren Suryalaya adalah anak-anak yang "tidak dekat dengan ayahnya." Hasil penelitian Rika Aulya Purnama, Sri Wahyuni menegaskan pula bahwa kedekatan anak kepada ibunya dikarenakan adanya kenyamanan emosional yang kuat seorang anak apabila berdekatan dengan ibunya. ${ }^{5}$

Berbagai penelitian di atas merupakan bukti nyata bahwa ketidakdekatan seorang ayah dengan anak-anaknya dapat menjadikan jurang pemisah yang semakin lebar, dan dapat menjadikan disharmonisasi jiwa pada anak. Mereka menjadi anakanak yang tidak nyaman dengan kehidupannya sendiri, menjadi anak yang selalu

\footnotetext{
${ }^{2}$ Beidi Dong, Marvin D Krohn, Exploring Intergenerational Discontinuity in Problem Behavior: Bad Parents With Good Children,Journal Youth Violence and Juvenile Justice, 2014, DOI: 10.1177/1541204014527119

${ }^{3}$ Raden Dimas Bagus Prabowo dan Mita Aswanti, Hubungan Attachment Ibu-Anak dan AyahAnak dengan Kemandirian pada Remaja Akhir, Jurnal Fakultas Psikologi Universitas Indonesia, 2014

${ }^{4}$ Azam Syukur Rahmatullah, Penanganan Kenakalan Remaja Pecandu NAPZA dengan Pendidikan Berbasis Kasih SAyang (Studi di Pondok Remaja Inabah XV Putra Pon-Pes Suryalaya Tasikmalaya) jurnal Literasi STIA Al-MaAta Yogyakarta, Volume IV, No l Juni 2013 ISSN; 2085-0344

${ }^{5}$ Rika Aulya Purnama, Sri Wahyuni, Kelekatan (Attachment) pada Ibu dan Ayah Dengan Kompetensi Sosial pada Remaja, Jurnal Psikologi, Volume 13 Nomor 1, Juni 2017
} 
gelisah dalam menjalani aktifitasnya, dan bahkan menjadi anak-anak yang rendah diri. $^{6}$

Berangkat dari pemarapan di atas itulah yang menjadikan alasan kuat bagi penulis untuk menggali lebih dalam tentang kelekatan ayah dengan anaknya. Bagaimana kelekatan anak bisa terbangun oleh ayah-anak atau anak-ayah agar pada akhirnya memiliki keberfungsian jiwa yang matang dan tidak mengalami krisis perilaku.

\section{Pembahasan}

\section{A. Kelekatan Anak-Ayah dan Ayah-Anak, Sebuah Keniscayaankah?}

Kedekatan dan kelekatan antara anak-ayah atau ayah-anak apakah ini merupakan keniscayaan atau tidak bisa diwujudkan? sebuah pertanyaan yang memang layak untuk dipertanyakan, mengingat banyaknya penelitian yang menunjukkan perihal effect-negative ketidakdekatan antara ayah-anak, anak-ayah yang menjadikan anak kehilangan suri tauladan dan kehilangan figur lekat seorang ayah. Hasil penelitian Yea Seul Pyun menyatakan bahwa anak-anak yang tidak dekat dengan ayahnya mengalami problem mentalnya, yang pada akhirnya membawa anak kepada kejiwaan-kejiwaan yang kosong, tidak berfungsi dan pada akhirnya perilaku mereka tidak menunjukkan keberfungsian positifnya. $^{7}$

Sarah Allen and Kerry Daly menjelaskan bahwa pentingnya peran ayah dalam mengasuh anak-anaknya, tidak hanya dibebankan kepada ibunya. ${ }^{8}$ Selama ini yang terjadi peran pengasuhan yang terkotak-kotak, seolah-olah pengasuhan anak hanya menjadi tugas utama seorang ibu, yang dekat dan lekat kepada anak adalah seorang ibu, sedangkan bapak memiliki tugas mencari nafkah untuk keluarga. Bapak tidak memiliki kewajiban yang sifatnya mutlak untuk mendekat dan melekat kepada anak, sehingga asumsi yang terbangun ketika seorang bapak pulang kerja, tidak merasa perlu untuk mendengar cerita

\footnotetext{
${ }^{6}$ Kartini Kartono, Patologi Sosial 2 Kenakalan Remaja, (Jakarta: PT Rajawali Pres, 2010), 57

${ }^{7}$ Yea Seul Pyun, The Influence of F ather-Child Relationship on Adolescents' Mental Health, Theses, Dissertations, and Other Capstone Projects, Minnesota State University - Mankato, 2014

${ }^{8}$ Sarah Allen and Kerry Daly, The Effects of Father Involvement:An Updated Research Summary of the Evidence, This project was funded by the Public Health Agency of Canada and the Social Sciences and Humanities Research Council CURA program. Centre for Families, Work \& Well-Being, University of Guelph2007. ISBN 0-88955-563-X978-0-88955-563-1
} 
anak di sekolah, tidak merasa perlu untuk mendengarkan keluh kesah anak dalam kesehariannya, atau pula tidak merasa perlu untuk berkomunikasi intim dengan anak. Kondisi yang demikian itulah yang menurut Sarah Allen and Kerry Daly banyak dijumpai di masyarakat dan menjadikan anak mengalami kebimbangan hidup.

Pernyataan Sarah Allen dan Kerry Daly dipertegas dengan hasil penelitian Yosra Sayahi Nahid Javadifar., dkk yang menyatakan bahwa kedekatan dan kelekatan seorang ayah kepada anak-anaknya idealnya sudah dibangun sejak masa pra-natal, yakni sejak dalam kandungan. ${ }^{9}$ Ayah seharusnya dekat dan mendekat kepada calon bayi dengan cara memberi perhatian yang hangat, komunikasi yang intim dengan calon bayi, memberi doa-doa yang mulia kepada calon bayi. Sayangnya, banyak calon ayah-ayah baru ataupun ayah-ayah lama yang tidak memperhatikan kondisi yang demikian. Adanya anggapan lagi bahwa masalah kehamilan dan komunikasi yang terjalin dengan jabang bayi adalah kewajiban mutlak seorang ibu, sebab berada di rahimnya. Sedangkan ayah hanya bertugas mencari nafkah. Semua pernyataan atau asumsi tersebut tentu tidaklah benar, bahkan cenderung fatal. Asumsi-asumsi yang semakin menjauhkan hubungan intim antara anak-ayah atau ayah-anaknya.

Berangkat dari berbagai ulasan di atas itulah memunculkan sebuah kewajaran apabila ada pertanyaan besar perihal apakah kelekatan ayah-anak, anak-ayah merupakan keniscayaan? jawabannya tentu saja akan menjadi sebuah keniscayaan manakala seorang ayah menyengaja dengan tulus untuk selalu mendekat, tingkat keperdulian yang tinggi, memberi perhatian positif kepada anak-anak mereka baik setelah lahir maupun jauh sebelum dilahirkan, yakni ketika masih di dalam kandungan. Namun tidak akan menjadi sebuah keniscayaan apabila seorang ayah menyengaja untuk menjauhi anak, membebani anak-anak mereka dengan permasalahan-permasalahan yang seyogyanya belum seharusnya mereka mengalami., lari dari tanggung jawab, komunikasi yang buruk. Ketika anak bayi atau di dalam kandungan ayah tidak memanusiawikan

${ }^{9}$ Yosra Sayahi, Nahid Javadifar, Bahman Cheraghian, Miaad Sayahi and, The Relationship Between Unwanted Pregnancy with Mother and Father Attachment to Infant, Shiraz E-Med J. 2017 ;18(12):el4066. doi: 10.5812/semj.14066. 
mereka, hal yang demikian inilah yang pada akhirnya kelekatan ayah-anak, anak-ayah tidak akan pernah terbangun dan terjalin dengan harmonis.

\section{B. Pondasi Dasar Bangunan Kelekatan Ayah-Anak, dan Anak-Ayah}

Ada beberapa pondasi dasar yang dijadikan sarana untuk membangun kelekatan antara ayah-anak dan anak-ayah, beberapa pondasi dasar tersebut diantaranya adalah:

Azam Syukur Rahmatullah dalam penelitiannya berjudul "Attachment Parenting dalam Perspektif Psikologi Pendidikan Islam" menyatakan bahwa ada beberapa bangunan dasar timbulnya kelekatan yang erat antara orang tuayang dalam hal ini bisa ayah-ibu dengan anak, atau ayah dengan anak, atau ibu dengan anak - tergantung keberadaan siapa yang ada di dalam rumah tersebut, yang masih hidup atau masih mendampingi anak. Pertama, Meniadakan kekerasan dalam mendidik anak, Kedua, menjauhkan dari sikap pilih kasih kepada anak, Ketiga, memberikan pengasuhan dan mendidik anak dengan service excelent yakni memberikan kenyamanan, kesenangan, keharmonisan dan rasa penghargaan kepada anak. Keempat, pola mengasuh dan mendidik kepada anak dengan tutur kata santun, bijak, menjauhkan dari amarah/emosi dalam katakata maupun perbuatan, suka memaafkan kepada anak, sehingga anak akan merasakan kedamaian yang sesungguhnya tatakala dekat dengan orang tua; ayah dan ibunya. ${ }^{10}$

Jane Brooks menambahkan unsur-unsur kelekatan yang bisa dibangun antara lain; Pertama, memberikan iklim lingkungan yang sehat kepada anak, yang nantinya bisa menjadi media pengembangan jiwa dan pikiran anak yang positif, Kedua, pemberian contoh yang tidak manipulatif kepada anak, Ketiga, membangun iklim emosional yang menggembirakan anak. ${ }^{11}$

Menurut Muhammad Nur Abdul Hafidz Suwaid bahwa unsur-unsur pembangun kelekatan anak harus disemaikan sejak anak di dalam kandungan,

\footnotetext{
${ }^{10}$ Azam Syukur Rahmatullah, Attachment Parenting dalam Perspektif Psikologi Pendidikan Islam, Jurnal An-Nidzam Jurnal Manajemen Pendidikan dan Studi Islam Pascasarjana IAINU Kebumen Vol. 1. No. 2 Mei-Agustus 2014 2011),10

${ }^{11}$ Jane Brooks, The Process of Parenting, terj. Rahmat Fajar, (Yogyakarta: Pustaka Pelajar,
} 
bukan setelah mereka lahir dan tumbuh pasca masa kelahiran, termasuk melekatkan anak-anak pada ranah spiritual-ilahiyyah juga idealnya sudah diberlakukan dan diajarkan sejak anak masih dalam kandungan. ${ }^{12}$ Apabila dirinci dalam sebuah tabel, maka akan terlihat beberapa pondasi dasar pembangun kelekatan ayah-anak dan anak-ayah, sebagai berikut:

Tabel 1

Pondasi Dasar Pembangun Kelekatan Ayah-Anak dan Anak-Ayah

\begin{tabular}{|c|c|c|}
\hline No & Unsur Dasar Pembangun Kelekatan & Keterangan \\
\hline 1 & $\begin{array}{l}\text { Tidak ada unsur kekerasan dalam mengasuh } \\
\text { anak }\end{array}$ & $\begin{array}{l}\text { Kekerasan dalam bentuk kekerasan } \\
\text { fisik, verbal maupun kekerasan } \\
\text { mental }\end{array}$ \\
\hline 2 & $\begin{array}{l}\text { Menjauhkan dari sikap pilih kasih dan } \\
\text { membeda-bedakan antara satu anak dengan } \\
\text { anak lain }\end{array}$ & $\begin{array}{l}\text { Anak akan merasa minder, tidak } \\
\text { percaya diri }\end{array}$ \\
\hline 3 & $\begin{array}{l}\text { Memberikan kenyamanan, keharmonisan, } \\
\text { menghargai anak dengan tulus-murni }\end{array}$ & $\begin{array}{l}\text { Hal ini agar anak akan merasa } \\
\text { dimanusiawikan sebagai manusia }\end{array}$ \\
\hline 4 & $\begin{array}{l}\text { Memberikan bahasa penyampaian kepada anak } \\
\text { dengan tutur kata yang santun, bijak dan } \\
\text { mendinginkan hati anak }\end{array}$ & $\begin{array}{l}\text { Hal yang demikian agar anak akan } \\
\text { merasa berada pada rahim kedua } \\
\text { setelah dilahirkan, yang di dalamnya } \\
\text { terdapat kenyamanan yang hakiki } \\
\text { sama seperti pada waktu di rahim } \\
\text { pertama, yakni rahim ibu. }\end{array}$ \\
\hline 5 & $\begin{array}{l}\text { Memberikan lingkungan-iklim yang sehat } \\
\text { kepada anak }\end{array}$ & $\begin{array}{l}\text { Salah satu hal yang dibutuhkan anak } \\
\text { adalah lingkungan yang } \\
\text { menyehatkan jiwa, yang memberi } \\
\text { pemaknaan hidup dan mampu } \\
\text { merubah kejiwaan mereka menjadi } \\
\text { jiwa yang positif }\end{array}$ \\
\hline 6 & Pemberian contoh yang tidak manipulatif & $\begin{array}{l}\text { Contoh dan tauladan yang mampu } \\
\text { melahirkan generasi-generasi yang } \\
\text { tidak manipulatif }\end{array}$ \\
\hline 7 & $\begin{array}{l}\text { Membangun iklim emosional-afektif yang } \\
\text { hangat dan intim kepada anak }\end{array}$ & $\begin{array}{l}\text { Iklim yang menjadikan anak kerasan } \\
\text { di rumah dan merasa terakui sebagai } \\
\text { seorang anak }\end{array}$ \\
\hline
\end{tabular}

Kedekatan dan kelekatan antara ayah-anak dan anak-ayah bisa dicontohkan melalui Surat Luqman, di mana terlihat bagaimana hubungan Luqman begitu harmonis terhadap anaknya. Hal tersebut tergambar dalam QS. Luqmān: 13-19, sebagai berikut:

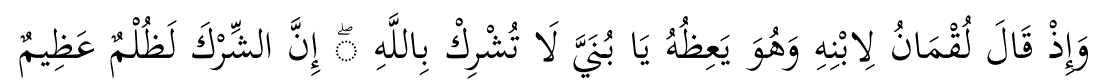

13. Dan (ingatlah) ketika Luqman berkata kepada anaknya, di waktu ia memberi pelajaran kepadanya: "Hai anakku, janganlah kamu mempersekutukan Allah, sesungguhnya mempersekutukan (Allah) adalah benar-benar kezaliman yang besar".

${ }^{12}$ Muhammad Nur Abdul Hafidz Suwaid, Prophetic Parenting; Cara Nabi Mendidik Anak, (Yogyakarta: Pro-U Media, 2010), 97 


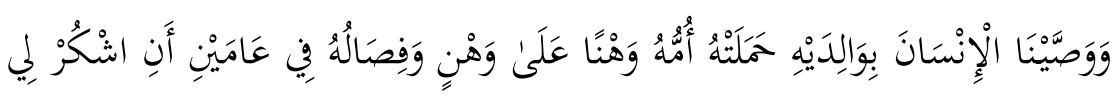

$$
\begin{aligned}
& \text { وَلِوَالِدَيْكَ إِلَيَّ الْمَصِيرُ }
\end{aligned}
$$

14. Dan Kami perintahkan kepada manusia (berbuat baik) kepada dua orang ibu-bapaknya; ibunya telah mengandungnya dalam keadaan lemah yang bertambah-tambah, dan menyapihnya dalam dua tahun. Bersyukurlah kepada-Ku dan kepada dua orang ibu bapakmu, hanya kepada-Kulah kembalimu.

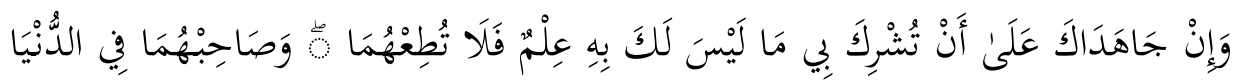

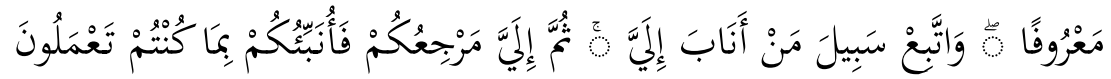

15. Dan jika keduanya memaksamu untuk mempersekutukan dengan Aku sesuatu yang tidak ada pengetahuanmu tentang itu, maka janganlah kamu mengikuti keduanya, dan pergaulilah keduanya di dunia dengan baik, dan ikutilah jalan orang yang kembali kepada-Ku, kemudian hanya kepadaKulah kembalimu, maka Kuberitakan kepadamu apa yang telah kamu kerjakan.

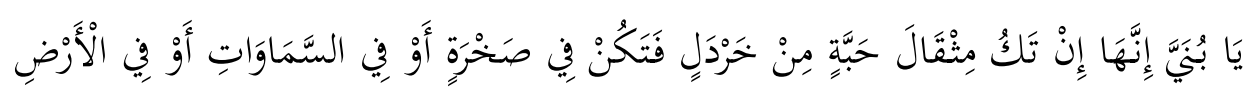

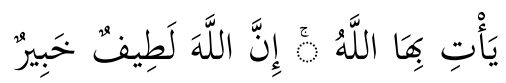

16. (Luqman berkata): "Hai anakku, sesungguhnya jika ada (sesuatu perbuatan) seberat biji sawi, dan berada dalam batu atau di langit atau di dalam bumi, niscaya Allah akan mendatangkannya (membalasinya). Sesungguhnya Allah Maha Halus lagi Maha Mengetahui.

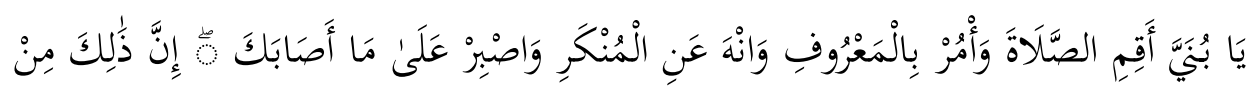

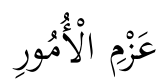

17. Hai anakku, dirikanlah shalat dan suruhlah (manusia) mengerjakan yang baik dan cegahlah (mereka) dari perbuatan yang mungkar dan bersabarlah terhadap apa yang menimpa kamu. Sesungguhnya yang demikian itu termasuk hal-hal yang diwajibkan (oleh Allah).

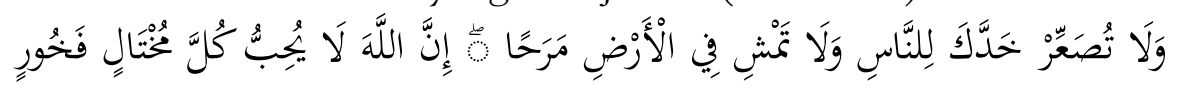

18. Dan janganlah kamu memalingkan mukamu dari manusia (karena sombong) dan janganlah kamu berjalan di muka bumi dengan angkuh. Sesungguhnya Allah tidak menyukai orang-orang yang sombong lagi membanggakan diri.

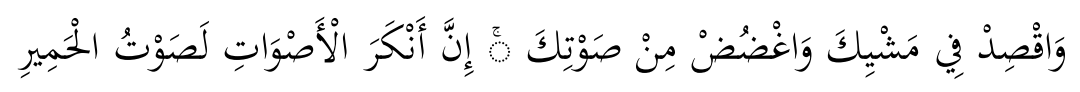

19. Dan sederhanalah kamu dalam berjalan dan lunakkanlah suaramu. Sesungguhnya seburuk-buruk suara ialah suara keledai. 
Ada beberapa tanda yang menunjukkan kedekatan emosional antara Luqman dengan anaknya melalui ayat di atas, diantaranya adalah:

1. Kedekatan dan kelekatan ayah-anak melalui bahasa yang menujukkan kasih sayang. Hal ini bisa dilihat dari bahasa penyampaian "hai anakku," kalimat "hai anakku" merupakan kalimat halus yang merujuk pada pengakuan kepada anaknya. Hal yang tidak layak dan tidak sepantasnya diucapkan yang menunjukkan ketidakdekatan dan kelekatan ayah-anak adalah apabila seorang ayah menyampaikan dengan kata" hai” saja, atau menyebut nama anak secara langsung. Hal yang demikian terkesan kurang "beretika, dan kurang mengakui keberadaan si anak."

2. Pemberian nasehat dengan bijaksana, tidak terkesan meluapkan emosi dan amarah, dan sifatnya mengajak dengan nada halus, tidak dengan nada kasar, merendahkan serta menjatuhkan anak.

3. Luqman memberikan pencerahan dan pemahaman kepada anaknya, sesuatu yang sifatnya "wajib," nasehat yang mencerahkan akan mengarahkan anak pada fase pemaknaan. Hal itulah yang dilakukan oleh Luqman kepada anaknya. Hal ini bisa dilihat dari pernyataan Luqman yang didalamnya ada kata "sesungguhnya." Kata sesungguhnya merupakan kata sambung untuk menta'kidkan yang sekaligus pula berupaya memahamkan dan meyakinkan bahwa apa yang akan dilakukan memiliki resiko buruk yang bisa menjauhkan keimanan kepada Allah Ta'ala. Hal yang demikian tidak diinginkan oleh Luqman sebagai seorang ayah yang benar-benar tunduk dan patuh kepada Allah.

C. Kelekatan Ayah-Anak, Anak-Ayah Sebagai Upaya Membangun Potensi Keberfungsian Jiwa Positif Anak

Memberfungsikan secara positif jiwa anak merupakan suatu usaha untuk memutihkan, memanusiawikan, dan menghidupkan kejiwaan anak agar senantiasa merasakan kedamaian, kenyamanan, keharmonisan, dan kebahagiaan yang sifatnya natural, dan tidak dibuat-buat. Anak-anak yang sehat jiwanya, dan berfungsi positif berarti memiliki kesehatan mental yang baik. Menurut Moeljono Notosoedirdjo dan Latipun salah satu ciri kesehatan mental adalah 
keberfungsian jiwa yang baik. ${ }^{13}$ Sedangkan menurut Sukanto \& A Dardiri Hasyim orang memiliki kesehatan mental memiliki perilaku positif yang menunjukkan kejiwaannya yang juga positif ${ }^{14}$. Dengan kata lain dapat diambil kesimpulan bahwa anak-anak yang mampu membangun potensi keberfungsian positif jiwa mereka adalah anak-anak yang sehat mentalnya.

Kondisi sehat jiwa anak idealnya memang perlu dibangun dari dalam dan luar, dan sifatnya berkelanjutan, bukan berkesudahan. Pembangunan yang berkelanjutan berarti adanya sifat yang "terus-menerus" dengan berbagai upaya yang sehat untuk membantu memberfungsikan kejiwaan anak, sehingga anak akan merasakan dampak positif dari berbagai upaya tersebut. Sedangkan pembangunan yang berkesudahan artinya tidak adanya kelanjutan dari usahausaha untuk menyehatkan jiwa anak tersebut, anak akan merasakan kehampaan sehingga dampaknya menjadi jiwa-jiwa yang liar, dan kering, yang pada akhirnya menyengsarakan kehidupan anak itu sendiri.

Salah satu bentuk upaya pembangunan dari dalam dan luar tersebut adalah mendekatkan dan melekatkan seorang ayah kepada anak-anaknya sejak dini. Ada beberapa hal yang sesungguhnya bisa diberlakukan oleh seorang ayah kepada anaknya sehingga terjalin komunikasi yang intens dan menyehatkan jiwa anak, beberapa di antaranya adalah:

1. Sejak di dalam kandungan seorang ayah sudah harus berkomunikasi dengan anak. Mereka diajak bercakap-cakap, mengelus-elus anak melalui perut ibu, diajak bercerita, bersenda gurau, mengajak berfikir, dan tidak terkesan meniadakan keberadaan mereka atau "seolah-olah tidak ada dan belum ada di dunia."Kesemua itu dilakukan oleh sang ayah, meski ibu pun idealnya melakukan hal yang lebih dari apa yang diperbuat ayah. Hasil penelitian dari Rochmah Nur Ichromi menyatakan bahwa hal yang idealnya dilakukan oleh seorang ayah, apalagi ibu kepada anaknya yang berada di dalam kandungan adalah melakukan pendidikan pranatal, dengan beberapa metode yang antara lain; metode doa, metode ibadah, metode bermain bersama, metode dialog, metode berkomunikasi bersama, metode bermain

\footnotetext{
${ }^{13}$ Moeljono Notosoedirdjo \& Latipun, Kesehatan Mental, Konsep dan Penerapan, (Malang :PT Universitas Muhammadiyah Malang, 2014), 13

${ }^{14}$ Sukanto \& Dardiri Hasyim, Nafsiologi; Refleksi Analisis tentang Diri dan Tingkah Laku Manusia, (Surabaya: PT Risalah Gusti, 1995), 39
} 
dan bernyanyi, metode zikir, dan metode membaca dan menghafal. ${ }^{15} \mathrm{Hal}$ yang demikian seharusnya dilakukan oleh seoarng ayah, tidak hanya diberlakukan hanya kepada seorang ibu.

2. Pasca kelahiran, seorang ayah ikut berperan menjadi "seorang ibu" yang mana dia ikut mengganti popok, membersihkan kotoran, menyuapi, memandikan, bergadang, yang kesemua itu sejatinya akan memperkaya afeksi dan emosional-lekat ayah, yang secara tidak langsung kedekatan dan kelekatan tersebut akan terbangun dari dalam diri ayah yang pada akhirnya akan ber-efect pada anak yang juga merasakan kedekatan dan kelekatan kepada ayahnya sejak dini. Berbeda apabila seorang ayah enggan berperan "menjadi seorang ibu" dan menyerahkan seluruh pengasuhan anak kepada ibunya, tentu saja yang demikian akan menjadikan bumerang untuk si ayah itu sendiri, yang pada akhirnya anak-anaknya menolak untuk dekat dan lekat kepada mereka, sebab sejak masa bayi sudah terbangun hal yang demikian.

3. Ngeloni Anak (meninabobokkan anak)

Menurut Azam Syukur Rahmatullah, yang dimaksud ngeloni anak adalah memeluk anak-anak mereka ketika tidur, dengan memberikan sentuhansentuhan dan usapan-usapan di kepala anak, atau tubuh anak, dengan penuh kasih sayang dan cinta yang alami tanpa adanya nuansa kebencian, amarah dan caci maki kepada anak, sehingga anak merasakan kenyamanan yang sangat, dan kehangatan jiwa yang memang dibutuhkan oleh mereka. ${ }^{16}$ Ngeloni anak ini idealnya juga dilakukan oleh ayah kepada anak-anaknya sejak mereka masih bayi. Karena pada umumnya selama ini yang ngeloni anak adalah "hanya ibunya", padahal seharusnya tidaklah demikian.

4. Senantiasa memeluk anak baik masa kedatangan ayah dari bekerja, atau masa kepergian ayah akan bekerja, dan masa -masa lainnya yang mana terjadi perjumpaan ayah dengan anak. Hal ini dikarenakan anak sejatinya membutuhkan perhatian, sentuhan hangat, dan kepedulian seorang ayah.

\footnotetext{
${ }^{15}$ Rochmah Nur Ichromi, Konsep Pendidikan Pranatal dalam Pandangan Dr.Mansur, M.A dan Ubes Nur Islam, Hasil Penelitian, Jurusan PAI Fakultas Tarbiyah Dan Keguruan, UIN Malang, 2016

${ }^{16}$ Azam Syukur Rahmatullah, Penguatan Perilaku "Ngeloni Anak" Oleh Ibu-Ayah Sebagai Upaya Menciptakan Keluarga Harmonis-Seimbang Sejak Dini, Jurnal Cendekia STAIN Ponorogo Jurnal Kependidikan dan Kemasyarakatan, Vol 14. No 1 Tahun 2016, ISSN-1693-1505 dan 2477-796X
} 
Umumnya yang terjadi, ketika masa kepergian ayah akan bekerja tidak sempat memeluk anak, ketika pulang bekerja ayah pun tidak memeluk anak, ketika bersama ada anak dalam satu ruangan, ayah lebih banyak berkomunikasi dengan media sosial (gadget) atau bahkan lebih konsen dengan televisi dan laptop, sedangkan anak-anaknya "tidak tersentuh" olehnya. ${ }^{17}$ Kondisi demikian, tentu saja menjadikan anak semakin "merasa jauh dari orang tuanya terutama ayahnya." Di sisi lain seorang ayah secara tidak langsung juga sudah membelajarkan kepada anak-anaknya untuk tidak menfungsikan jiwa dan perasaannya dengan baik, yang mungkin saja ketika anak tumbuh nantinya akan menjadi anak-anak yang tidak mampu berperan positif bagi lingkungannya.

Ada beberapa tanda apabila seorang ayah berhasil lekat dengan anakanaknya, di antaranya adalah:

1. Anak merasa riang ketika bersama-sama ayah, apalagi jika ada ibunya, dengan kata lain "ayah-ibu senantiasa bersama-sama bersama anak," memberikan waktu untuk anak, sebab pada dasarnya anak membutuhkan keutuhan keluarganya.

2. Anak merasakan waktu begitu cepat jika sedang bersama ayah, hal ini dikarenakan ayah selalu berhasil membuat hati anak bahagia, tertawa lepas, bermain bersama, sehingga tanpa disadari anak waktu sudah berlalu.

3. Adanya rasa ingin terus mengulang kembali masa-masa kedekatan bersama ayah. Hal ini merupakan salah satu tanda kelekatan (attachment) yang berhasil. Menurut Azam Syukur Rahmatullah, jika anak merasakan tidak mau berpisah dengan figur lekatnya, atau ingin mengulang masamasa kebersamaan dengan figur lekat tersebut, berarti anak sudah benar-

\footnotetext{
${ }^{17}$ Hasil penelitian Jeny Radesky dari Boston Center menyatakan bahwa orang tua masa sekarang lebih perhatian kepada gadget dari pada anak-anaknya sendiri. Mereka lebih fokus menatap gadget daripada menatap dan mengajak komunikasi intim kepada anak-anak mereka. Hal ini terlihat dari penelitian sejumlah 55 kelompok orang tua dan anak yang sedang makan di rumah makan cepat saji. Dari hasil penelitian tersebut menunjukkan secara jelas bahwa 40 dari 55 kelompok orang tua selalu menatap gadget selama makan, dan mereka lebih banyak menaruh perhatian ke perangkat mobile ketimbang anak-anak mereka.Orang tua Masa Kini Lebih Peduli Gadget Dibanding Anak, http:/tekno.liputan6.com/read/2041368/orangtua-masa-kini-lebih-peduli-gadget-ibanding anak, diakses pada tanggal 10 Januari 2018
} 
benar menyatu dengan figur lekat, dan tentu saja menjadi suatu hal yang positif untuk mengarahkan anak menuju perilaku yang positif pula. ${ }^{18}$

4. Anak selalu membanggakan ayahnya, dan menyampaikan kepada semua kawan dan orang-orang yang dikenal menceritakan tentang kehebatan ayahnya yang selalu membuat keluarga bahagia meski bukan orang punya.

5. Anak akan mencontoh perilaku ayah karena kekaguman kepada dirinya. Hal-hal yang baik dan positif akan sanantiasa diteladani anak dari ayahnya.

Sedangkan tanda-tanda ketidakberhasilan ayah yang tidak lekat dengan anak-anaknya tergambar pada beberapa ciri berikut ini:

1. Anak akan merasa "tidak memiliki ayah" meskipun ayahnya berada di depan mata. Ada atau tidak adanya ayah bagi si anak sama saja, adanya ayah di dalam kehidupannya pun tidak membawa "kebermanfaatan baginya", dan ketidakhadiran ayah dalam kehidupannya pun juga sama tetap tidak membawa keberuntungan bagi hidupnya.

2. Seorang anak tidak pernah menyebut ayahnya di hadapan siapapun, bahkan jika ditanya tentang sosok ayah, si anak tidak akan pernah bersedia menjawab. Si anak akan lebih banyak bercerita tentang ibunya, yang dianggapnya sebagai sosok ayah dan sekaligus ibu baginya, meski sejatinya sang ayah masih hidup dan tinggal bersama diri si anak dalam satu rumah.

3. Si anak enggan berpergian bersama manakala ayah ikut serta, hal ini karena si anak tidak bisa berlama-lama dalam satu ruangan atau satu tempat bersama si ayah. Bagi si anak, melihat ayah seperti halnya sesosok monster yang mengerikan, dan membuatnya teringat akan perlakuan-perlakuan si ayah terhadap dirinya, yang benar-benar menyakitkan bagi si anak.

4. Anak akan berlama-lamakan diri di luar rumah, atau lebih banyak bermain dengan kawan-kawannya, bahkan mungkin lebih memillih

${ }^{18}$ Azam Syukur Rahmatullah, Attachment Parenting dalam Perspektif Psikologi Pendidikan Islam, Jurnal An-Nidzam Jurnal Manajemen Pendidikan dan Studi Islam Pascasarjana IAINU Kebumen Vol. 1. No. 2 Mei-Agustus 2014 
tinggal di tempat kawan atau ngekost dari pada pulang, yang pada akhirnya mau tidak mau akan berjumpa dengan ayahnya.

Dari beberapa tanda-tanda yang diuraikan di atas memperlihatkan bagaimana peran ayah sangat besar dalam menentukan keberfungsian positif dan negatifnya jiwa sang anak. Apabila kedekatan dan kelekatan seorang ayah dapat terbangun dengan baik, maka akan mengarahkan anak pada keberfungsian jiwa anak yang positif. Demikian pula sebaliknya, jika kedekatan dan kelekatan ayah dan anak tidak mampu terbangun dengan baik, maka yang terjadi adalah keberfungsian jiwa anak akan negatif. Hal tersebut selaras dengan pernyataan Rogers yang mengatakan bahwa orang yang bisa berfungsi dengan sepenuhnya adalah orang-orang yang mendapatkan lingkungan sehat dari sekitarnya, terutama dari orang terdekatnya. ${ }^{19}$ Lingkungan sehat tersebut akan menjadikan mereka manusia-manusia yang mampu mengaktualisasikan diri dengan baik.

\section{Catatan Akhir}

Berdasarkan dari pemaparan di atas dapatlah diambil kesimpulan bahwa peran ayah dalam membesarkan anak-anaknya tidak bisa dipandang sebelah mata. Anak membutuhkan kedekatan dan kelekatan kepada ayahnya, demikian pula sejatinya seorang ayah pun membutuhkan kedekatan dan kelekatan kepada anakanakya. Oleh karenanya, menjadi suatu keharusan apabila di dalam keluarga seorang ayah mengembangkan kedekatan dan kelekatan kepada anak-anaknya sejak dini, agar nantinya anak-anak akan menyambut baik usaha ayahnya dalam upaya merekatkan hubungan dengan mereka.

\section{Daftar Rujukan}

Allen, Sarah and Kerry Daly (2007), The Effects of Father Involvement:An Updated Research Summary of the Evidence, This project was funded by the Public Health Agency of Canada and the Social Sciences and Humanities Research Council CURA program. Centre for Families, Work \& Well-Being, University of Guelph. ISBN 0-88955-563- X 978-0-88955-563-1

${ }^{19}$ C.R. Rogers, On Becoming a Person: A Therapist's View of Psychotherapy (Boston : Houghton Mifflin, 1961), 186

AL-MURABBI Vol. 5, No. 1, Juli 2018 ISSN 2406-775x (Print), ISSN 2540-7619 (Online) 
Bagus Prabowo, Raden Dimas dan Aswanti, Mita (2014), Hubungan Attachment IbuAnak dan Ayah-Anak dengan Kemandirian pada Remaja Akhir, Jurnal Fakultas Psikologi Universitas Indonesia

Beidi Dong, Marvin D Krohn (2014), Exploring Intergenerational Discontinuity in Problem Behavior: Bad Parents With Good Children,Journal Youth Violence and Juvenile Justice, DOI: $10.1177 / 1541204014527119$

Brooks, Jane (2011), The Process of Parenting, terj. Rahmat Fajar, Yogyakarta: Pustaka Pelajar

Ichromi, Rochmah Nur, Konsep Pendidikan Pranatal dalam Pandangan Dr.Mansur, M.A dan Ubes Nur Islam, Hasil Penelitian, Jurusan PAI Fakultas Tarbiyah Dan Keguruan, UIN Malang, 2016

Kartono, Kartini, Patologi Sosial 2 Kenakalan Remaja, Jakarta: PT Rajawali Pres, 2010

Notosoedirdjo, Moeljono \& Latipun (2014), Kesehatan Mental, Konsep dan Penerapan, Malang :PT Universitas Muhammadiyah Malang

Purnama, Rika Aulya, Sri Wahyuni (2017), Kelekatan (Attachment) pada Ibu dan Ayah Dengan Kompetensi Sosial pada Remaja, Jurnal Psikologi, Volume 13 Nomor 1, Juni

Pyun, Yea Seul (2014), The Influence of F ather-Child Relationship on Adolescents' Mental Health, Theses, Dissertations, and Other Capstone Projects, Minnesota State University - Mankato

Rahmatullah, Azam Syukur (2013), Penanganan Kenakalan Remaja Pecandu NAPZA dengan Pendidikan Berbasis Kasih SAyang (Studi di Pondok Remaja Inabah XV Putra Pon-Pes Suryalaya Tasikmalaya) jurnal Literasi STIA Al-MaAta Yogyakarta, Volume IV, No l Juni, ISSN; 2085-0344

Rahmatullah, Azam Syukur (2014), Attachment Parenting dalam Perspektif Psikologi Pendidikan Islam, Jurnal An-Nidzam Jurnal Manajemen Pendidikan dan Studi Islam Pascasarjana IAINU Kebumen Vol. 1. No. 2 Mei-Agustus

Rahmatullah, Azam Syukur (2016), Penguatan Perilaku "Ngeloni Anak" Oleh Ibu-Ayah Sebagai Upaya Menciptakan Keluarga Harmonis-Seimbang Sejak Dini, Jurnal Cendekia STAIN Ponorogo Jurnal Kependidikan dan Kemasyarakatan, Vol 14. No 1 Tahun, ISSN-1693-1505 dan 2477-796X

Rogers, C.R. (1961), On Becoming a Person: A Therapist's View of Psychotherapy, Boston : Houghton Mifflin

Suwaid, Muhammad Nur Abdul Hafidz (2010), Prophetic Parenting; Cara Nabi Mendidik Anak, Yogyakarta: Pro-U Media

Sukanto \& Dardiri Hasyim, Nafsiologi; Refleksi Analisis tentang Diri dan Tingkah Laku Manusia, Surabaya: PT Risalah Gusti, 1995

Violet Lai, Gerald Zeng, Chi Meng Chu (2016), Violent and Nonviolent Youth Offenders: Preliminary Evidence on Group Subtypes, Doi: 10.1177/1541204015615193

Yosra Sayahi, Nahid Javadifar, Bahman Cheraghian, Miaad Sayahi (2017) , The Relationship Between Unwanted Pregnancy with Mother and Father Attachment to Infant, Shiraz E-Med J.;18(12):el4066. doi: 10.5812/semj.14066. 